\title{
UTILIZAÇÃO DA METODOLOGIA DMAIC EM COMUNIDADES PESQUEIRAS ARTESANAIS NO SUDESTE DO BRASIL
}

Guilherme Arpini REIS ${ }^{1}$; Talita Seckim JULIO ${ }^{1}$; Vanielle Aparecida do Patrocinio GOMES ${ }^{1}$; Rodrigo Randow de FREITAS ${ }^{1 *}$

${ }^{1}$ Universidade Federal do Espírito Santo - UFES-CEUNES

*email: digorandow @gmail.com

Recebido em 14/06/2016

Resumo - Estimativas mais recentes apontam que no mundo existam cerca de 39 milhões de pescadores, sendo que $90 \%$ destes estão envolvidos com a pesca de pequena escala - ou artesanal tradicional - sendo que, nos países em desenvolvimento, esta proporção é maior. A atividade pesqueira no Estado do Espírito Santo tem se tornado uma das principais fontes de renda e oferta de alimentos para um grande número de famílias, principalmente, para as pequenas cidades litorâneas. Porém, os pescadores encontram diversas dificuldades neste setor. Assim, o presente estudo, realizado nas comunidades pesqueiras de Pedra D'agua, Guriri e Barra Nova, todas localizadas em São Mateus, teve como objetivo aplicar a metodologia DMAIC nos processos de produção, beneficiamento e comercialização do pescado. Por meio dos dados coletados foi possível aplicar diversas ferramentas da qualidade, de modo a avaliar, rigorosamente, os processos observados. Os resultados demonstraram as características e o nível de qualidade nos processos, propondo algumas ações corretivas e de melhorias para os processos, gerando possibilidades de elaborações de políticas públicas futuras. As melhorias mais importantes se encontram em relação à aquisição de novos equipamentos para todos os processos como equipamentos ligados à refrigeração como câmaras frigoríficas e freezers, equipamentos para auxiliar o transporte do pescado do porto até o seu destino, ferramentas para realizar o beneficiamento do pescado e uma melhor infraestrutura, possibilitando que os pescadores consigam agregar um maior valor ao produto.

Palavras-Chave: Diagrama de Afinidades, Diagrama de Causa e Efeito, PDCA, Pesca artesanal, Seis Sigma

\section{APPLICATION OF THE DMAIC METHODOLOGY IN FISH PROCESSES IN ARTISANAL FISHING COMMUNITIES IN SOUTHEASTERN BRAZIL}

Abstract - More recent estimates indicate that in the world there are about 39 million fishermen, with $90 \%$ of these involved in small-scale fishing - or traditional craftsmanship - wherein in developing countries, this proportion is higher. The fishing activity in the state of Espirito Santo has become a major source of income and food supply to a large number of families, especially for small coastal towns. However, fishermen have faced several difficulties in this sector. The present study, carried out in fishing communities Pedra D'agua, Guriri and Barra Nova, all located in São Mateus, aimed to apply the DMAIC methodology in production processes, processing and commercialization of fish. Through the data collected, it was possible to apply various quality tools in order to rigorously assess the observed processes. The results demonstrated the characteristics and processes' quality level, proposing some corrective actions and improvements to the processes generating possibilities of future public policies elaborations. The most important improvements are in relation to the acquisition of new equipment for all processes and equipment related to refrigeration and cold stores and freezers, equipment to assist the fish transport from the port to its destination, tools to carry out the fish processing and better infrastructure, enabling fishermen to be able to add greater value to the product.

Keywords: Affinity Diagram, Cause and effect diagram, PDCA, Artisanal fishing, Six Sigma 


\section{INTRODUÇÃO}

Em virtude das exigências cada vez maiores em termos de qualidade e produtividade mundialmente, inicia-se, no final da década de 1980 nos EUA, a utilização de um método de trabalho para melhoria de produtos e processos, denominado de Seis Sigma (CORONADO \& ANTONY, 2002), sendo este método uma estratégia que possui como principal foco a redução de custos e a melhoria da qualidade de produtos e processos, com o consequente aumento da satisfação de clientes e consumidores e da lucratividade da organização (WERKEMA, 2012).

O Seis Sigmas se popularizou na década de 1990 e teve como líder John F. Welch, o então presidente da empresa General Electric (GE) (WATSIN, 2001). A metodologia utilizada como principal ferramenta de desenvolvimento é a DMAIC (Definição, Medição, Análise, Melhoria e Controle). O DMAIC baseia-se no ciclo original do PDCA (Planeje - Execute - Verifique - Ações Corretivas), que é um método que auxilia na prática do controle e que se constitui a base da melhoria (Campos, 2014), sendo aplicado tanto em esforços de Melhoria de Processo quanto em Projeto/Reprojeto (HARRY \& SCHROEDER, 2000).

Considerando a crise global do setor pesqueiro, que tem afetado profundamente a qualidade de vida dos povos do mar, em particular a dos pescadores artesanais, identificou-se a oportunidade de estudar os processos da atividade. Sendo que, comunidades litorâneas sofrem os impactos resultantes de estilos de vida social e ecologicamente predatórios, oriundos da expansão urbana, industrial e portuária, intensificados, ainda, pelo decréscimo dos níveis de produtividade biológica dos ecossistemas litorâneos (VIEIRA, 1991).

Estimativas mais recentes apontam que no mundo existam cerca de 39 milhões de pescadores e 156 milhões de pessoas dependendo, indiretamente, da pesca. Globalmente, $90 \%$ dos pescadores estão envolvidos com a pesca de pequena escala, ou artesanal tradicional, sendo que nos países em desenvolvimento, esta proporção é maior. Considerando que mais de uma pessoa da família pode trabalhar no setor e que muitos pescadores, dos países em desenvolvimento, não possuem nenhum tipo de cadastro, as cifras supracitadas podem ser estimativas conservadoras (FAO, 2002).

O Brasil produz aproximadamente 1,4 milhão de toneladas/ano de pescado, propiciando um PIB pesqueiro de R $\$ 5$ bilhões, ocupando 800 mil profissionais entre pescadores e aquicultores e gerando 3,5 milhões de empregos diretos e indiretos (MPA, 2011), com isso, o potencial de crescimento se mostra favorável e o país pode se tornar um dos maiores produtores mundiais. 
Quanto ao Estado do Espírito Santo, este possui uma linha de costa com cerca de $470 \mathrm{~km}$ de extensão (FUNDAÇÃO PROZEE, 2006). A atividade pesqueira é considerada, basicamente, artesanal devido ao sistema produtivo ser predominante de carácter familiar e de subsistência e de parceria ou armadores.

Assim, com o exposto, caracterizando e analisando os processos de produção, beneficiamento e comercialização local, o presente estudo tem o intuito de contribuir com a gestão costeira, orientação das ações perante os atores locais, potenciais investidores e a possibilidade de elaboração de políticas públicas, a fim de aprimorar a atividade, satisfazer as demandas crescentes por alimentos e permitir um planejamento eficiente, contribuindo para um pleno desenvolvimento socioeconômico da cadeia produtiva das comunidades de Pedra D’Água, Guriri e Barra Nova no município de São Mateus, Espírito Santo.

\section{Material e Métodos}

O presente estudo foi desenvolvido nas comunidades de pescadores artesanais e tradicionais

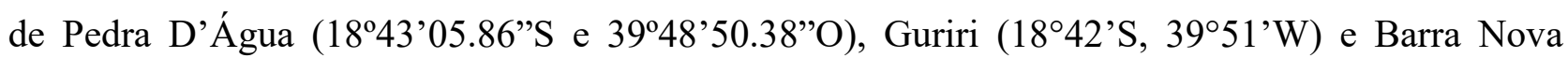
(18 $57^{\circ}$ S, 39² $\left.45^{\prime} \mathrm{W}\right)$, todos localizados no município de São Mateus, ES, Brasil. A Figura 1 representa as áreas de pesca das comunidades de Pedra D’Água, Guriri e Barra Nova.

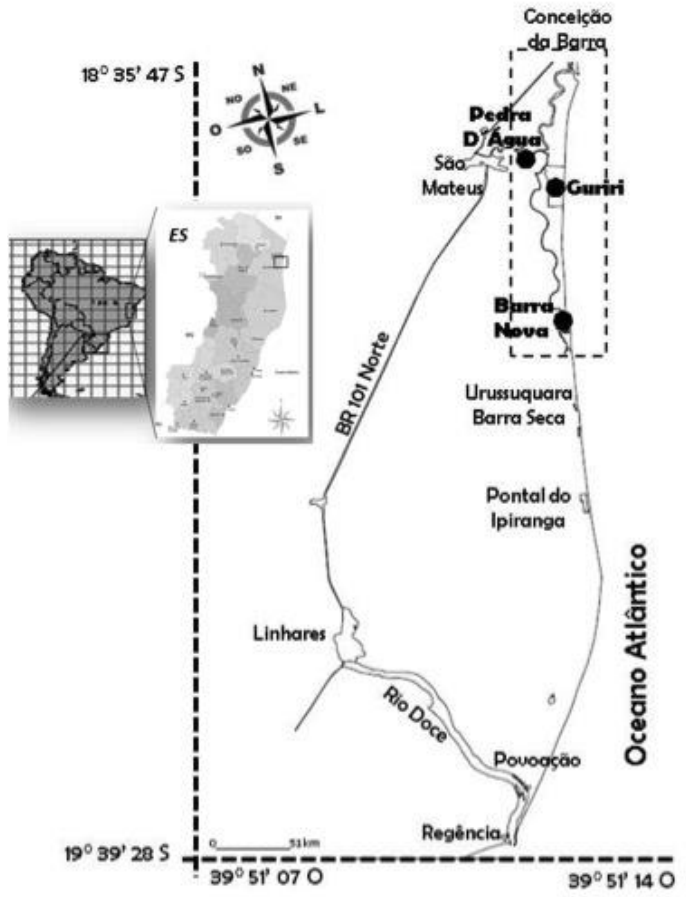

Figura 1. Localização geográfica das comunidades Pedra D’água, Guriri e Barra Nova estudadas. Contextualizadas no âmbito da América do Sul. Fonte: Elaborado pelos autores. 
Quanto à abordagem, este trabalho, sob o ponto de vista de sua natureza, é classificado como estudo de campo. A pesquisa foi desenvolvida por meio da observação direta, e por ser desenvolvida no próprio local em que ocorrem os fenômenos, seus resultados foram mais fidedignos (GIL, 2002). A abordagem utilizada foi qualitativa e quantitativa, tendo o ambiente natural como uma fonte direta para coleta de dados em que se requer aplicação de recursos e técnicas estatísticas (LACERDA, et al., 2007).

De forma a gerar informações adequadas para o desenvolvimento do estudo, na coleta de dados foram utilizadas observação e entrevista, que ocorreram entre os dias 02 e 24 de fevereiro de 2015. A entrevista foi padronizada e estruturada, seguindo um roteiro previamente estabelecido e as perguntas feitas pelo entrevistador foram predeterminadas (LAKATOS \& MARCONI, 2003).

Com relação ao método de amostragem foi utilizado o snowball sampling, conhecido como cadeia de informantes ou método bola-de-neve. Com isso, a amostragem adotada foi a não probabilística por acessibilidade, sendo usados os elementos acessíveis para a coleta dos dados, buscando a fidedignidade, a eficiência e a representatividade das características dos dados (GIL, 2002).

Adotou-se essa estratégia de coleta de dados, pois se mostrou a forma mais ágil e eficiente para compreender os principais aspectos socioeconômicos, ambientais e produtivos, procurando informações acerca do que os atores sabiam, esperavam ou desejavam da atividade, com o intuito de descrever as atividades pesqueiras (GIL, 2002).

Primeiramente, foi realizada a elaboração de um Fluxograma do Processo, no qual foram listadas todas as atividades necessárias para a realização do processo e mostradas em sequência lógica das etapas, em que cada simbologia representa uma função. Para se obter indicadores de referências para as etapas dos processos de Produção, Beneficiamento e Comercialização foi necessário realizar pesquisas, coletar informações sobre como são realizadas essas etapas em locais que possuem uma maior infraestrutura e técnicas mais avançadas, de modo que se pudesse ter uma base para realizar uma comparação com as características das áreas pesqueiras em estudo.

Segundo Werkema (1995), o Diagrama de Causa e Efeito é utilizado para mostrar a relação existente entre o resultado de um processo (efeito) e os fatores (causas) desse processo que podem prejudicar o resultado. Assim, este diagrama age como um guia para a identificação da causa raiz do problema e para a determinação de ações a serem tomadas. 
Quanto ao diagrama de afinidades, este é uma ferramenta da qualidade que tem como objetivo agrupar um grande número de ideias, opiniões e informações em grupos, conforme a afinidade que apresentam entre si. É construído através das ideias, das opiniões e outras preocupações sobre determinado problema, organizando-se em grupos baseados em uma relação natural que exista entre elas, estimulando a criatividade e facilitando o aparecimento de novas ideias e enfoques por meio da participação dos membros, o que gera um melhor entendimento daquilo que está acontecendo.

Por fim, obtidos os resultados das ferramentas da qualidade utilizadas, culminou-se no momento de serem analisados os resultados e, com isso, estabelecer ações corretivas para sanar os problemas que estão ocorrendo e propor melhorias para os processos de Produção, Beneficiamento e Comercialização do pescado nas áreas de estudo, fazendo com que se tornem mais eficientes.

\section{Resultados E DiscuSSÃo}

Por meio das entrevistas realizadas, em Pedra D’Água obteve-se um total de 11 questionários aplicados, em Guriri, 15 e, por último, em Barra Nova, 59. Sendo que esta quantidade foi limitada pela oferta de pescadores no momento da aplicação dos questionários, constituindo assim um total de 85 entrevistados. Assim, com base no princípio do snowball e a quantidade de entrevistados, a amostra foi considerada suficiente, pois o padrão das repostas se manteve devido à semelhança na realidade dos entrevistados.

A captura dos pescados, nas comunidades de Guriri e Barra Nova, foi realizada no mar e a de Pedra D’Água no rio São Mateus. A manjuba (Anchoviella lepidentostole) representa 25\% do total de espécies capturadas na Pedra D’Água, já em Guriri a espécie mais capturada é a pescadacambucu (Cynoscion virescens), correspondendo a 68\% das espécies capturadas. Já na comunidade de Barra Nova, a espécie com maior captura é o camarão (Xiphopenaeus kroyeri), correspondendo a aproximadamente $49 \%$ do total de espécies capturadas. A partir dessa breve caracterização e dentre os demais dados coletados, apresentados no decorrer desse manuscrito, dividiu-se o estudo nas fases: Definir, Medir, Analisar, Melhorar e Controlar, expostas a seguir.

$\mathrm{Na}$ fase definir, no caso o business case, nas comunidades em estudo, a pesca foi considerada de extrema importância na geração de renda, sendo a única ou a principal fonte de renda para, aproximadamente, sessenta famílias, segundo as entrevistas realizadas com os pescadores dessas comunidades. Neste cenário, é fundamental que se analise todo o processo do pescado visando 
corrigir os erros que ocorrem e propor melhorias para garantir uma melhor eficiência ao processo.

Com o intuito de facilitar o entendimento de todas as operações, que ocorrem no processo do pescado, foi elaborado um fluxograma que mostra os processos e decisões envolvidas no processo produtivo, apresentado na Figura 2.

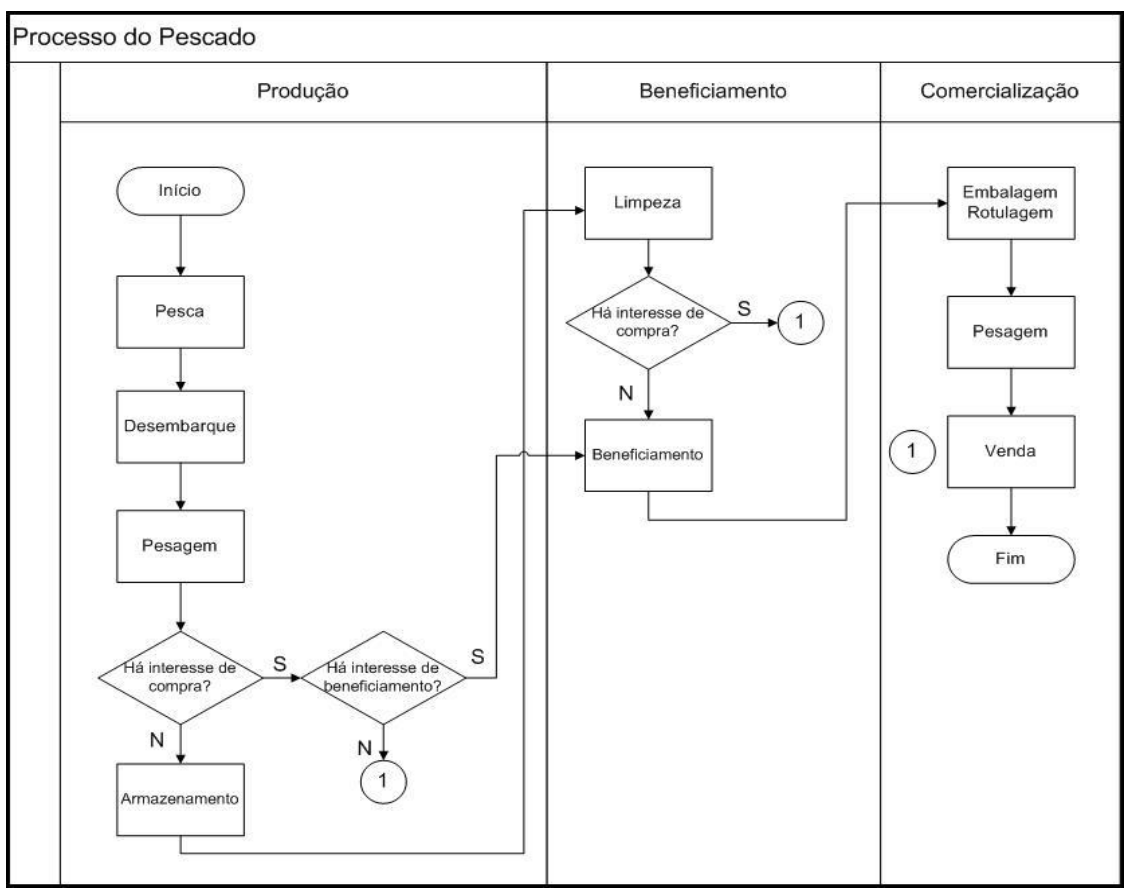

Figura 2. Fluxograma dos processos e decisões envolvidas no processo produtivo do pescado. Fonte: Elaborado pelos autores.

Quanto à fase medir, de acordo com cada etapa, que compõe o processo do pescado, e segundo a teoria de Nave (2002) foram estabelecidos os indicadores de referências, com ênfase em requisitos que afetam a eficiência do processo. Os indicadores estão presentes na Tabela 1.

Tabela 1. Índices de Referência que afetam a eficiência do processo. Fonte: Adaptado de Machado, et al. (2010).

\section{Índices de Referência}

\begin{tabular}{llll}
\hline 1 & Fumantes & 11 & Lavam o barco a cada pescaria \\
\hline 2 & Já contraíram doença infectocontagiosa & 12 & Utilizam água tratada para lavagem \\
\hline 3 & Vão ao dentista quando sentem dor & 13 & Utilizam produto sanitizante na lavagem \\
\hline 4 & Atuam há mais de 10 anos na pesca & 14 & Realizam lavagem do pescado a bordo \\
\hline 5 & São proprietários das embarcações & 15 & Realizam separação do pescado a bordo \\
\hline 6 & Pescam diariamente & 16 & Manipulam pescado na residência \\
\hline 7 & Animal doméstico a bordo & 17 & Realizam venda direta ao consumidor \\
\hline 8 & Não utilizam gelo & 18 & Concluíram Ensino Fundamental \\
\hline 9 & Utilizam gelo de origem duvidosa & 19 & Concluíram Ensino Médio
\end{tabular}


Importante mencionar que as análises neste estudo foram feitas apenas qualitativamente, pois com as referências bibliográficas e os dados analisados não foi possível mensurar os tipos e a quantidade de não conformidades, que ocorrem no processo.

$\mathrm{Na}$ fase analisar, para ser possível identificar os fatores que podem influenciar na baixa confiabilidade do processo do pescado, nas comunidades em estudo, foram elaborados Diagramas de Causa e Efeito para os processos de produção, beneficiamento e comercialização. Estes diagramas foram então utilizados para o levantamento e a apresentação visual das possíveis causas e de como essas teriam relação com o problema.

Também, para que fosse possível identificar os principais causadores de problemas foram utilizados, como base, os indicadores de desempenho, estabelecidos por Machado, et al. (2010).

Assim, o processo de produção envolve a captura, desembarque, pesagem e o armazenamento, incluindo o manuseio entre as operações. As possíveis causas para a falha no processo de produção com relação às máquinas seriam as más condições do equipamento, o que pode auxiliar na não conservação do pescado. Já com relação à mão de obra, os problemas encontrados foram a falta de treinamento e qualificação dos pescadores, já que em muitos casos esta atividade é passada de geração para geração, além disso, muitos pescadores não possuem estudos. Apesar da tecnologia estar cada vez mais evoluída, a pesca artesanal dificilmente usufrui da mesma, aplicando ainda equipamentos já precários, que consequentemente influenciam diretamente na qualidade do peixe. Por fim, o meio ambiente traz como fator as condições climáticas, já que a região de estudo é uma região de altas temperaturas, que não contribui para a conservação do pescado. De forma sucinta, as causas foram listadas na Figura 3.

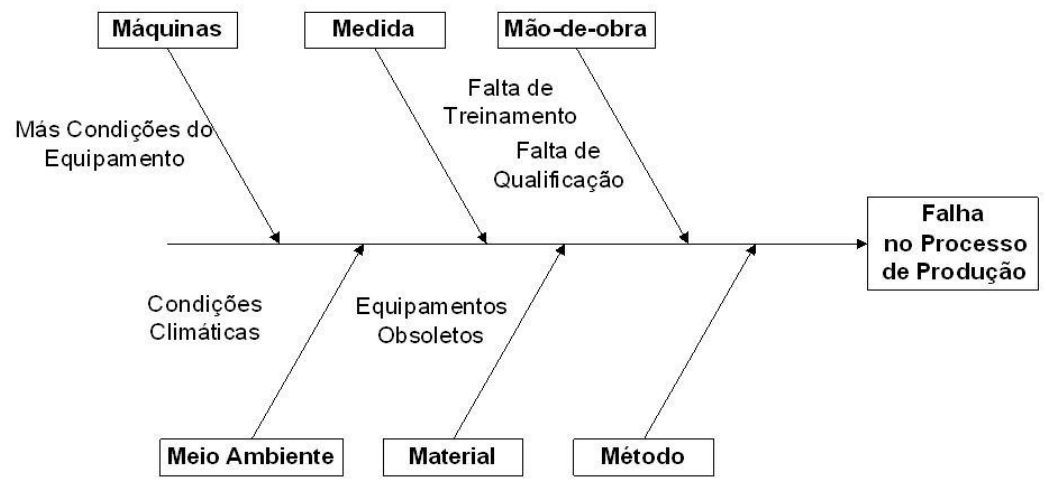

Figura 3. Diagrama de Causa e Efeito no Processo de Produção. Fonte: Elaborado pelos autores. 
Já o processo de beneficiamento consiste na limpeza e no beneficiamento do pescado de modo a agregar um valor maior ao produto. O diagrama de causa e efeito do processo de beneficiamento é mostrado na Figura 4.

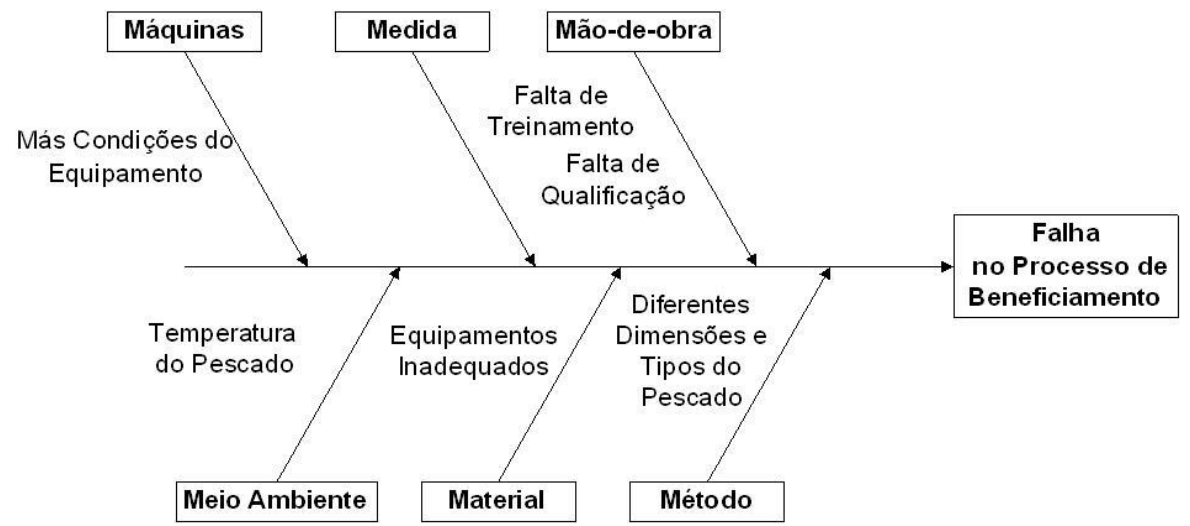

Figura 4. Diagrama de Causa e Efeito no Processo de Beneficiamento. Fonte: Elaborado pelos autores.

O processo de comercialização engloba as operações de embalagem/rotulagem, pesagem e venda do pescado. Diferentemente dos outros diagramas, neste a medida possui uma causa de falha, já que nesta etapa são usados equipamentos como balanças, que se forem utilizados de forma equivocada geram erros. As possíveis causas para a falha no processo de comercialização foram descritas na Figura 5.

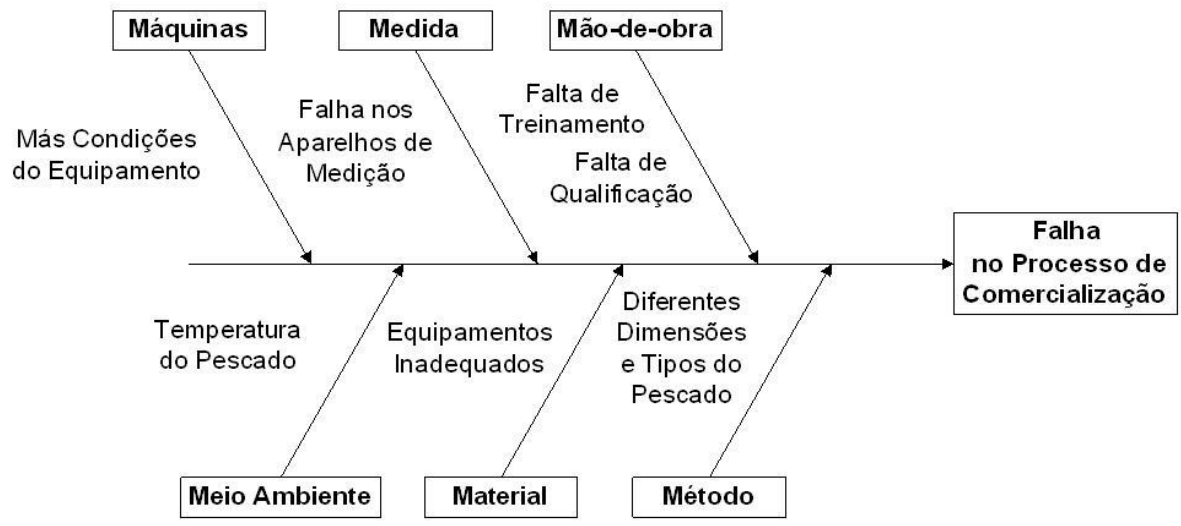

Figura 5. Diagrama de Causa e Efeito no Processo de Comercialização. Fonte: Elaborado pelos autores.

Assim, ao analisar os Diagramas de Causa e Efeito, desenvolvidos para o processo do pescado, foram identificadas nove possíveis causas diferentes, e essas causas são também chamadas de X's vitais do problema. Por isso, surge a necessidade de utilização do diagrama de afinidade (ou método KJ), o qual é empregado para esclarecer a natureza, a forma e a extensão dos 
problemas, agrupando ideias ou opiniões sob a forma de informações verbais, segundo similaridade (RAMOS, 2009).

Assim, os X's vitais dos problemas detectados acima foram alocados em três grupos diferentes, sendo estes: equipamentos, nível de conhecimento e ambiente, de modo a esclarecer a origem destes e facilitar a proposição de soluções. No grupo equipamentos foram alocadas as seguintes causas: condição dos equipamentos, equipamentos inadequados/obsoletos, diferentes dimensões e tipos de pescado e falha nos aparelhos de medição, no nível de conhecimento englobam a falta de treinamento e a de qualificação e, por fim, no grupo ambiente estão as condições climáticas e a temperatura do pescado. $\mathrm{O}$ diagrama de afinidades resultante pode ser visualizado na Figura 6.

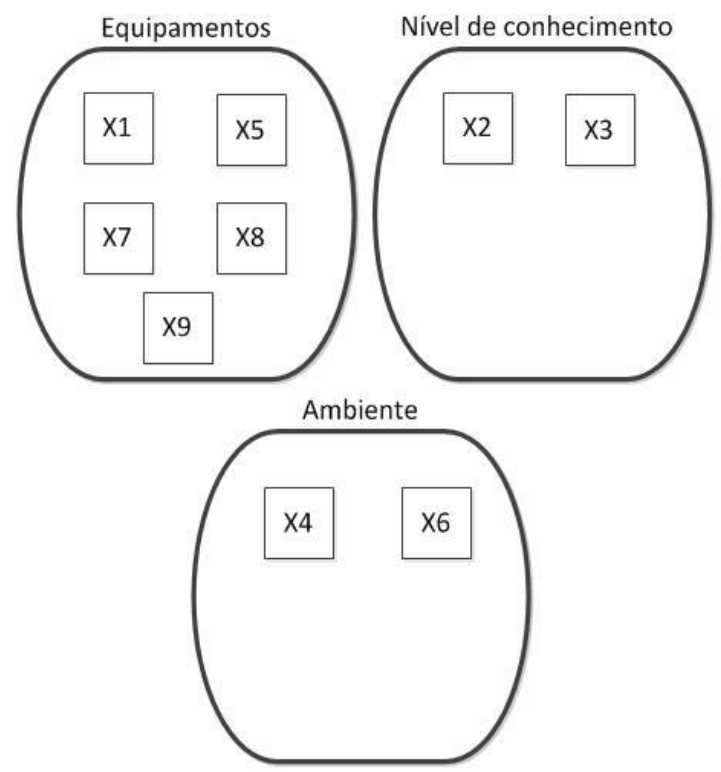

Figura 6. Diagrama de Afinidades dos X's vitais. Fonte: Elaborado pelos autores.

Até este ponto do estudo, foram utilizadas ferramentas, métricas e métodos a fim de identificar, medir e verificar qual o impacto das possíveis falhas presentes no processo. Passou-se assim para a fase melhorar, na qual ocorreu a proposição de variadas sugestões de melhorias, que atuaram de forma direta nas causas raízes (X’s vitais), que estão alocadas após a descrição do X vital.

A partir do agrupamento acima teve-se a condição dos equipamentos como primeiro $\mathrm{X}$ vital, uma vez que a condição dos equipamentos que foram utilizados ao longo de todo processo é de suma importância e gerador de problemas, sendo que a falha e/ou mau funcionamento de um destes 
afetará, de forma direta, o processo. Para este, sugeriu-se a criação de um programa de manutenção preventiva, em que a cada período preestabelecido seja feita a verificação de todos os equipamentos do processo e todos os componentes defeituosos deverão ser trocados. Dessa forma, se fará com que o processo opere com alta confiabilidade.

$\mathrm{O}$ segundo $\mathrm{X}$ vital demonstra que a falta de treinamento dos profissionais que de alguma forma participam do processo da atividade pesqueira pode ser um fator gerador de problemas e, consequentemente, qualquer falha de sua parte pode afetar diretamente o processo.

Com relação à falta de treinamento dos colaboradores sugere-se que o responsável pela embarcação realize, periodicamente, treinamentos específicos para cada área de atuação do processo como a utilização de sonares, GPS, aparelhos de comunicação e navegação, assim aumentando o nível de excelência do processo.

Em estudo realizado nos municípios de Calçoene e Oiapoque no Amapá foi observado que as embarcações possuem, pelo menos, um instrumento de navegação, em todas as embarcações foi constatada a presença da bússola, como principal instrumento e essencial nas pescarias, tais modificações foram observadas por Lima (2011) em estudo realizado em Calçoene e Oiapoque no Amapá.

O terceiro X vital expõe que profissionais sem a devida qualificação, que estejam atuando em alguma área do processo em estudo, podem ser uma das causas geradoras de problemas. Quanto à falta de qualificação, a sugestão é cobrar da Prefeitura e dos órgãos governamentais a implantação de cursos de capacitação para os colaboradores envolvidos no processo e para todas as pessoas, que tenham interesse de atuar nesse segmento, para que quando for necessária a contratação de novos colaboradores, estes já sejam capacitados para realizar a função desejada.

Corroborando, segundo Osório (2008), no Equador foi implantado, com sucesso, um guia de boas práticas de pesca no setor pesqueiro artesanal. Esse guia é direcionado aos pescadores artesanais e manipuladores de pescado, com o objetivo de melhorar as formas de manuseio e conservação do pescado a bordo, e mostra a necessidade do uso do gelo, rapidez no processo, higiene do manipulador, da embarcação, dos equipamentos, do certificado de saúde do pescador, proibição de animais a bordo, entre outras importantes considerações.

Já as condições climáticas foram consideradas o quarto X vital e demonstra que esta situação afeta, diretamente, no processo de captura do pescado, pois se o clima estiver desfavorável, impossibilita a realização da mesma. 
No que diz respeito às condições climáticas, sugere-se que sejam utilizados equipamentos meteorológicos nas embarcações, para que seja possível enfrentar condições adversas do mar com uma maior segurança para os pescadores e para a embarcação.

Nos municípios de Calçoene e Oiapoque no Amapá, segundo Lima (2011), foi constatada a utilização da bússola e de outros equipamentos de navegação, como: rádio VHF, GPS e sonda foram observados. Nas embarcações de maior porte a diferença é que estas possuem mais instrumentos, que auxiliam a navegação tornando-as sofisticadas, como a presença do aparelho navegador e o rastreador.

Este $\mathrm{X}$ vital demonstra que a utilização de equipamentos obsoletos, em diferentes partes do processo pode acarretar com que a eficiência seja menor do que a esperada, gerando perdas.

$\mathrm{O}$ sexto $\mathrm{X}$ vital se vincula com a temperatura do pescado desde a captura até a comercialização, sendo este aspecto de extrema importância, e se a mesma não for controlada afeta diretamente a qualidade do produto.

Por se tratar de um produto que é comercializado limpo/eviscerado ou até mesmo sujo, a temperatura em que este é mantido é de extrema importância para garantir a qualidade, com isso sugeriu-se que seja realizado um controle da temperatura no armazenamento, fazendo com que essa fique dentro do limite permitido. Por exemplo, na cidade de São Mateus a única fábrica de gelo em funcionamento é privada e está localizada no bairro Seac, e não possui capacidade para atender a toda demanda do município e a fábrica de gelo de Pedra D’Água está fechada devido ao não cumprimento de normas técnicas de funcionamento, fazendo com que seja necessário a compra de gelo em municípios vizinhos, como, por exemplo, em Conceição da Barra. Isso difere da comunidade de Arraial do Cabo, Rio Janeiro que possui duas fábricas de gelo em funcionamento, auxiliando na garantia da qualidade e a perecibilidade do pescado (MENDONÇA, et al., 2010).

$\mathrm{O}$ sétimo $\mathrm{X}$ vital demonstra que a utilização de equipamentos, que possuam função similar, mas que não sejam os adequados para realização de determinada função podem afetar diretamente a qualidade do produto, com isso se torna necessário o uso das ferramentas corretas.

Quanto à utilização de equipamentos obsoletos e/ou inadequados sugeriu-se o investimento na compra de equipamentos mais modernos, principalmente, ligados à refrigeração como câmaras frigoríficas e freezers, equipamentos para auxiliar o transporte do pescado do porto até o seu destino, ferramentas para realização do beneficiamento do pescado como descabeçamento, filetamento e a instalação de um guincho nas comunidades de Guriri e Barra Nova, para auxiliar a 
retirada da embarcação do mar.

Corroborando, segundo Santos (2005), no nordeste paraense, 13,07\% dos entrevistados no estudo tiveram acesso a financiamento bancário para custeio e, principalmente, de investimento para aquisição de embarcações, de equipamentos e para treinamento de recursos humanos.

Em sequência, o oitavo $\mathrm{X}$ vital expressa que devido às diferenças existentes entre espécies de pescado, os procedimentos para beneficiamento e comercialização são diferentes, sendo tal aspecto entendido como uma causa geradora de problemas. Com relação às diferentes dimensões e tipos de pescado, a proposta de melhoria é que sejam desenvolvidos métodos de beneficiamento para cada espécie de pescado, com isso aumentando o valor agregado ao produto.

Corroborando, segundo Kalikoski \& Vasconcelos (2013), no estuário de Lagoa dos Patos, Brasil, uma pequena parte dos pescadores processam seu pescado para agregar valor ao produto e aumentar a renda familiar. As espécies que mais costumam ser processadas são o linguado, peixerei, traíra e o bagre, e esse processamento ocorre com maior frequência nos municípios de Tapes, Tavares, Mostardas e Arambaré.

Por último, falha nos aparelhos de medição é o nono $\mathrm{X}$ vital, uma vez que os aparelhos de medição utilizados em todos os processos devem estar devidamente calibrados e regulados para que não interfiram no desempenho do processo. Com relação à falha nos aparelhos de medição a sugestão é que se verifique com maior frequência a calibração e regulagem dos aparelhos de medição, fazendo com que o processo funcione com maior eficiência e controle.

Segundo a União Europeia (2011), o novo sistema de controle estabelece regras precisas no que diz respeito à pesagem das capturas, que deverá ser fiável. Todas as capturas devem ser pesadas no momento do desembarque para assegurar o registo correto, e a sua regulagem dos aparelhos de medição é realizada periodicamente.

Quanto à fase controlar, que é a última etapa do DMAIC, o principal objetivo é o de procurar garantir que as melhorias e os benefícios obtidos com as mudanças realizadas com as etapas anteriores sejam mantidos. Assim, algumas sugestões para o processo em estudo são: realização periódica de treinamentos para os colaboradores; reuniões regulares com os responsáveis pelo processo de modo a sugerir possíveis melhorias e informar a ocorrência de não conformidades e o estabelecimento de metas para os processos. 


\section{CONCLUSÕES}

A utilização do DMAIC no ramo da pesca é muito escassa, com isso há dificuldade em encontrar material bibliográfico, que auxilie no desenvolvimento do mesmo, não tornando possível aplicar todas as ferramentas que compõem o método, isso reforça quanto à importância da disseminação dessa metodologia na atividade pesqueira.

As comunidades pesqueiras, em estudo, possuem características semelhantes, com isso a partir dos resultados obtidos ficou evidente a necessidade de melhorias ao longo de todo o processo do pescado nessas regiões.

As melhorias mais importantes se encontram em relação à aquisição de novos equipamentos para todos os processos e, principalmente, uma melhor infraestrutura para os pescadores como píer ou trapiche para desembarque do pescado, uma estrutura que possibilite uma maior visibilidade dos produtos, fazendo com que as vendas aumentem, tendo o maior beneficiamento do pescado, possibilitando que os pescadores consigam agregar um maior valor ao produto.

Além disso, foi possível observar a falta de qualificação e treinamento dos mesmos, já que a grande maioria daqueles pescadores possui essa profissão porque algum ente familiar próximo também é ou até mesmo pela necessidade. Na região não existe nenhuma qualificação nem treinamento que pudesse ser oferecido para os mesmos, para que eles pudessem ir adquirindo mais conhecimento e, consequentemente, ajudasse no resultado final, ou seja, um pescado de boa qualidade.

A não ocorrência de reuniões também atrapalha no desenvolvimento da pesca no município, algo aconselhável a se fazer é que as cooperativas locais marquem com seus pescadores reuniões para se sejam discutidas as dificuldades de cada um e até mesmo troca de experiências, já que o problema de um pode auxiliar na resolução do problema do outro, além de que nessas reuniões possam ser traçadas metas que os mesmos devem alcançar, porque quando se tem algo a ser comprido e a pessoa vai ser cobrada com relação aquilo, logo a mesma irá se esforçar mais para alcançar os objetivos.

Foi constatado também, que as comunidades pesqueiras em estudo não possuem nenhum tipo de coleta e análises sistemáticas de dados em relação aos processos de produção, beneficiamento e comercialização, o que torna mais complicado a avaliação do andamento de cada processo e as possíveis melhorias que podem ser implementadas.

Como sugestão para trabalhos futuros, destaca-se a necessidade de elaboração de um modo 
de realizar a análise quantitativa dos dados, tornando possível a aplicação de todas as ferramentas existentes no DMAIC. Por exemplo, o controle estatístico do processo (CEP) e calcular o nível sigma do processo.

\section{REFERÊNCIAS}

FUNDAÇÃO PROZEE - Fundação de Amparo à Pesquisa de Recursos Vivos na Zona Economicamente Exclusiva. (2006). Relatório Final do Projeto de Monitoramento da Atividade Pesqueira no Litoral do Brasil. Brasília, DF. Acessado em 15 de junho de $2015 \mathrm{em}$ http://www.mpa.gov.br/files/docs/Informacoes_e_Estatisticas/Monitoramento-da-AtividadePesqueira-no-Litoral-do-Brasil.pdf.

MPA - Ministério da Pesca e Aquicultura. (2011). Boletim Estatístico da Pesca e Aquicultura. Brasília, DF. Acessado em 16 de junho de 2015 em http://www.mpa.gov.br/files/docs/Boletim_MPA_2011_pub.pdf.

CAMPOS, V. F. (2014). TQC - Controle da Qualidade Total: No estilo japonês. Falconi Consultores de Resultado, 286p.

CORONADO, R. B. \& ANTONY, J. Critical success factors for the successful implementation of six sigma projects in organizations. The TQM Magazine, 14: 92-99.

FAO. (2002). Report of the Sustainable Fisheries Livelihoods Program (GCP/INT/735/UK) and FAO Advisory Committee on Fisheries Research Joint Working Party on Poverty in Small-Scale Fisheries. Rome, Italy, 27 p.

GIL, A. C. (2002). Como elaborar projetos de pesquisa. São Paulo, SP: Atlas.

HARRY, M. J. \& SCHROEDER, R. (2000). Six Sigma: The Breakthrough Management Strategy Revolutionizing the World's Top Corporations. Currency, The University of Virginia.

KALIKOSKI, D. C. \& VASCONCELLOS, M. (2013). Estudo das condições técnicas, econômicas e ambientais da pesca de pequena escala no estuário da Lagoa dos Patos, Brasil: uma metodologia de avaliação. FAO, Roma, Itália.

LACERDA, D. P.; SILVA, E. R. P.; NAVARRO, L. L. L.; OLIVEIRA, N. N. P. \& CAULLIRAUX, H. M. (2007). Algumas caracterizações dos métodos científicos em Engenharia de Produção: uma análise de periódicos nacionais e internacionais. In: XXVII Encontro Nacional de Engenharia de Produção (pp. 1-10). 
LAKATOS, E. M. \& MARCONI, M. A. (2003). Fundamentos de Metodologia Científica. São Paulo, SP: Atlas.

LIMA, V. A. V. (2011). Embarcações e artes de pesca utilizadas nos municípios de Calçoene e Oiapoque, no estado do Amapá, Brasil [Monografia de Bacharel]. Macapá (AP): Universidade do Estado do Amapá.

MACHADO, T. M.; FURLAN, E. F.; NEIVA, C. R. P.; CASARINI, L. M.; PÉREZ, A. C. A.; NETO, M. J. L. \& YOMITA, R. Y. (2010). Fatores que afetam a qualidade do pescado na pesca artesanal de municípios da costa sul de São Paulo, Brasil. Boletim do Instituto de Pesca, 36: 213 223.

MENDONÇA, F. M.; VALLE, R. A. B. \& COUTINHO, R. (2010). A cadeia produtiva da pesca artesanal em Arraial do Cabo: análise e propostas de melhoria. In: XXX Encontro Nacional de Engenharia de Produção.

NAVE, D. (2002). How to compare six sigma, lean and theory of constraints, A framework for chosing what's best for your organization. Quality Progress, 73-79. Acessado em 6 de julho de 2015 em http://www.lean.org/Search/Documents/242.pdf.

OSÓRIO, V. (2008). Implementación de las buenas practicas de pesca (BPP) em el sector pesqueiro artesanal. In: Reunión Regional Panamericana de Control de Calidad, Inspección y Tecnología de Productos Pesqueros. Guayaquil, Equador.

RAMOS, A. W. (2009). Estatística II. São Paulo: Departamento de Engenharia de Produção da EPUSP, 2009 (Apostila didática).

SANTOS, M. A. S. (2005). A Cadeia Produtiva da Pesca Artesanal no Estado do Pará: Estudo de Caso no Nordeste Paraense. Revista Amazônia Ciência e Desenvolvimento, 1: 61:81.

VIEIRA, P. (1991). Rumo à revolução azul: contribuição à pesquisa de estratégias de desenvolvimento sustentável em ecossistemas litorâneos do sul do Brasil [Programa de PósGraduação]. Florianópolis (SC): Universidade Federal de Santa Catarina.

WATSIN, G. H. (2001). Cycles of learning: observations of Jack Welch. Six Sigma Forum Magazine, 1: 13-17.

WERKEMA, C. (1995). As Ferramentas da Qualidade no Gerenciamento dos Processos. Belo Horizonte, MG: Werkema. 
Reis et al.

Rev. Bras. Eng. Pesca 10(1): 01-16, 2017

Artigo

WERKEMA, C. (2012). Lean Seis Sigma: Introdução às Ferramentas do Lean Manufacturing. Belo Horizonte, MG: Werkema. 